\title{
Chronic intermittent hypoxia promoted lung cancer stem cell-like properties via enhancing Bach1 expression
}

Shengyu HaO ${ }^{1,2+}$, Xiaodan Zhu ${ }^{1,2+}$, Zilong Liu ${ }^{1}$, Xiaodan $\mathrm{Wu}^{1,2}$, Shanqun $\mathrm{Li}^{1,2^{*}} \mathbb{D}$, Pan Jiang ${ }^{1,2^{*}}$ and Liyan Jiang ${ }^{1,2^{*}}$

\begin{abstract}
Background: An adverse role for obstructive sleep apnea (OSA) in cancer aggressiveness and mortality has recently emerged from clinical and animal studies, and the reasons have not been fully determined. Cancer stem cells (CSCs) are regarded as the main cause of carcinoma metastasis. So far, the relationship between OSA and lung CSCs has not been explored.

Method: In the present study, we established an orthotopic mouse model of primary lung cancer and utilized chronic intermittent hypoxia $(\mathrm{ClH})$ exposure to mimic OSA status.

Results: We observed that $\mathrm{CIH}$ endows lung cancer with greater metastatic potential, evidenced by increased tumor growth, tumor seeding, and upregulated CSC-related gene expression in the lungs. Notably, the transcription factor BTB and CNC homology 1 (Bach1), a key factor in responding to conditions of oxidative stress, is increased in lung cancer after $\mathrm{ClH}$ exposure in vitro and in vivo. Meanwhile, exposing lung cancer cells to $\mathrm{ClH}$ promoted cell proliferation, clonal diversity, induced stem-like cell marker expression, and gave rise to CSCs at a relatively higher frequency. Furthermore, the increase of mitochondrial ROS (mtROS) and CSC-marker expression induced by CIH exposure was abolished in Bach1 shRNA-treated lung cancer cells.
\end{abstract}

Conclusions: Our results indicated that $\mathrm{CIH}$ promoted lung CSC-like properties by activating mtROS, which was partially mediated by Bach1.

Keywords: Obstructive sleep apnea, Chronic intermittent hypoxia, Cancer stem cells, Lung cancer, Bach1

\section{Background}

Obstructive sleep apnea (OSA) is a highly prevalent disorder characterized by repetitive occlusion of the upper airway during sleep that results in chronic intermittent hypoxia $(\mathrm{CIH})$ [1]. OSA is associated with a wide array of morbidities and mortalities including metabolic syndrome, cardiovascular and cognitive disorders [2]. Besides, accumulating evidence of animal models and

\footnotetext{
*Correspondence: li.shanqun@zs-hospital.sh.cn; jppanpan@126.com; jiang_ liyan2000@126.com

†Shengyu Hao and Xiaodan Zhu contributed equally to this work ${ }^{1}$ Department of Pulmonary Medicine, Zhongshan Hospital, Fudan University, 180 Fenglin Road, Shanghai 200032, China

Full list of author information is available at the end of the article
}

clinical researches has revealed that OSA exacerbated tumor progression and metastasis, which have been reported in breast cancer [3], colorectal cancer, prostate cancer, melanoma $[4,5]$, renal carcinoma [6], and lung cancer $[7,8]$. Notably, a recently published study prospectively provided evidence that about $50 \%$ of lung cancer patients have moderate to severe OSA. The relationship between OSA and lung cancer has been explored in recent years. However, the underlying mechanism for $\mathrm{CIH}$ deteriorating tumor remains obscure.

Lung cancer is on rising globally and is the main cause of cancer-related death worldwide [9]. The cancer stem cells (CSCs) involved in the lung cancer process have been explored and well established [10].

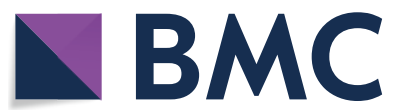

(c) The Author(s) 2021. Open Access This article is licensed under a Creative Commons Attribution 4.0 International License, which permits use, sharing, adaptation, distribution and reproduction in any medium or format, as long as you give appropriate credit to the original author(s) and the source, provide a link to the Creative Commons licence, and indicate if changes were made. The images or other third party material in this article are included in the article's Creative Commons licence, unless indicated otherwise in a credit line to the material. If material is not included in the article's Creative Commons licence and your intended use is not permitted by statutory regulation or exceeds the permitted use, you will need to obtain permission directly from the copyright holder. To view a copy of this licence, visit http://creativecommons.org/licenses/by/4.0/. The Creative Commons Public Domain Dedication waiver (http://creativeco mmons.org/publicdomain/zero/1.0/) applies to the data made available in this article, unless otherwise stated in a credit line to the data. 


\section{(See figure on next page.)}

Fig. 1 Lung cancer in $\mathrm{CIH}$-treated mice has greater CSC-like potential. a The timeline of this experiment. Briefly, after injected with urethane, mice were cultured for 6 months, then exposed to $\mathrm{ClH}$ for 1 month. All mice were harvest at the end of the experiment. $\mathbf{b}$ Survival rates of $\mathrm{C} 57 \mathrm{Bl} / 6$ wild-type male mice. Tumor $+\mathrm{Nor}, \mathrm{n}=12$, Tumor $+\mathrm{CH}, \mathrm{n}=12$. $\mathbf{c}$ The representative images of cancer loci in lungs from Tumor + Nor and Tumor $+\mathrm{ClH}$ groups. $\mathbf{d}$ The number of cancer loci observed in the lungs of mice. Data are shown as mean $\pm \mathrm{SEM}$. e Images of lung cancer nodules in H\&E-stained lungs of mice. ( $\mathbf{f}$ and $\mathbf{g}$ ) The protein levels of HIF-1a, CD44, ABCG2, Nanog, SOX2, and Oct4 in the lung cancer nodules were detected by western blot analysis. GADPH expression served as a loading control. Data are shown as mean \pm SEM. Error bars represent the mean. ${ }^{*} P<0.05$, ${ }^{* *} P<0.01$ and ${ }^{* *} P<0.001$. CIH chronic intermittent hypoxia, Nor normoxia, CSC cancer stem cell

CSCs are described as a subpopulation of tumor cells with the capacity to self-renew, differentiate, and promote tumor growth. They are responsible for metastases development and recurrence after therapy $[11,12]$. Lung CSCs have been previously isolated based on the presence of cell surface markers, including CD133 and CD44 [13, 14]. Hypoxia is increasingly recognized as owing the potential to exert a significant effect on the maintenance and evolution of CSCs $[15,16]$. In contrast to continuous hypoxia, $\mathrm{CIH}$ in patients with OSA is a unique physiological state with a phase of posthypoxic re-oxygenation. It is characterized by higher frequency, more serious hypoxia, and larger variation in blood oxygen saturation. However, little is known about the effect of OSA-like CIH on CSCs and the underlying mechanisms.

Reactive oxygen species (ROS), especially mitochondrial ROS (mtROS), is considered as a core factor in the pathogenesis of OSA-related diseases [16]. Though many researchers have demonstrated the connection between ROS production and CSCs, the role of ROS in cancer initiation and progression is controversial. Cancer cells can generate high levels of ROS [17]. Although ROS is often beneficial for tumor cells, specific forms of ROS can stimulate pro-tumorigenic signaling pathways by oxidizing and inactivating tumor suppressor proteins $[18,19]$. Bach1 is considered as a key factor in responding to conditions of oxidative stress and is associated with poor survival and metastasis in lung cancer patients [20]. Furthermore, we found that Bach1 can promote lung cancer stem cell phenotypes in our previous research (has not been published).

However, the effects of CIH on CSCs and its possible role in tumor metastatic phenotype are unknown and the role of Bach1 plays in CIH-promoted lung cancer is unclear. Based on previous studies, we hypothesized that the adverse effects of $\mathrm{CIH}$ on tumor proliferation and invasion would be partly mediated via CSCs. Our findings uncover that $\mathrm{CIH}$ plays a role in promoting CSC-like property, in which Bach1 and mtROS are activated. Our study suggests the possibility of developing CSC-targeting agents for lung cancer treatment in OSA patients.

\section{Materials and methods}

\section{Experimental animals}

C57BL/6 male mice of 8 weeks of age were purchased from the Nanjing Model Animal Center and bred in the animal facility of Zhongshan Hospital Fudan University according to the National Institutes of Health Guidelines for the Humane Treatment of Laboratory Animals. All procedures involving mice were approved by Zhongshan Hospital Institutional Animal Care and Use Committee by the Helsinki Declaration of 1975 . Mice were treated with urethane $(1 \mathrm{~g} / \mathrm{kg}$, Sigma, St. Louis, MO, USA) in total $0.2 \mathrm{ml}$ PBS by intraperitoneal injection with a gap of $48 \mathrm{~h}$ in a week for 6 weeks. At 6 months after urethane injection, the mice were randomly assigned to two groups ( $\mathrm{n}=12$ per group): (I) Tumor + Nor group: mice in tumor group cultured under normoxic conditions; (II) Tumor + CIH group: mice in tumor group exposed to $\mathrm{CIH}$. The model of $\mathrm{CIH}$ was established according to our previous research [21]. Briefly, mice were exposed to 1 -min period of $\mathrm{CIH}$ cycle in a chamber, and the oxygen concentration was adjusted between 4 and $21 \%$. Nitrogen was delivered to the chambers at a rate sufficient to achieve a fraction of inspired oxygen (FiO2) of 4-7\% within $30 \mathrm{~s}$ and maintain this level of $\mathrm{FiO}_{2}$ for $10 \mathrm{~s}$. Then, oxygen was introduced to achieve $\mathrm{FiO} 2$ of $20-21 \%$ within $30 \mathrm{~s}$. This model mimics a rate of 60 apneas $/ \mathrm{h}^{-1}$, which is typical of severe OSA and performed for $8 \mathrm{~h} /$ day (8:0016:00) for 1 month. The timeline was shown in Fig. 1a. After $8 \mathrm{~h}$ at the end of the last $\mathrm{CIH}$ cycle, mice were immediately sacrificed, and lung lobes were carefully separated from the mice. The number of carcinoma colonies per lung was counted after anterior and posterior image acquisition.

\section{Cell culture and $\mathrm{CIH}$ modeling in vitro}

A549 and SPCA1 cells were purchased from the Chinese Academy of Sciences Shanghai Cell Bank and cultured in RPMI-1640 supplemented with $10 \%$ fetal bovine serum in a humidified atmosphere containing $5 \% \mathrm{CO}_{2}$ at $37^{\circ} \mathrm{C}$. The medium was changed at 2-day intervals and cells replated at $80-90 \%$ confluence. $\mathrm{CIH}$ or normoxia model in vitro was performed as our previous study [22]. Briefly, cells were cultured in a computer-controlled incubator 

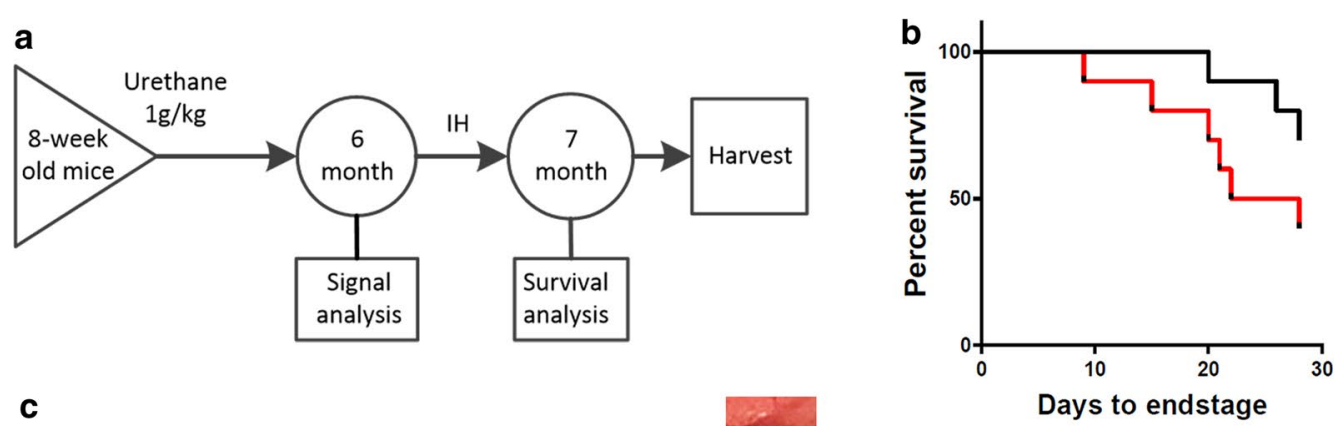

C

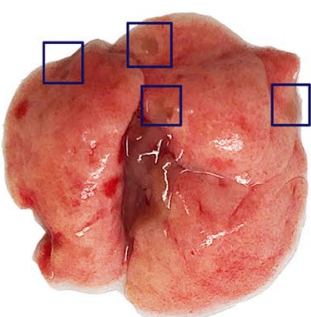

Tumor +Nor

e

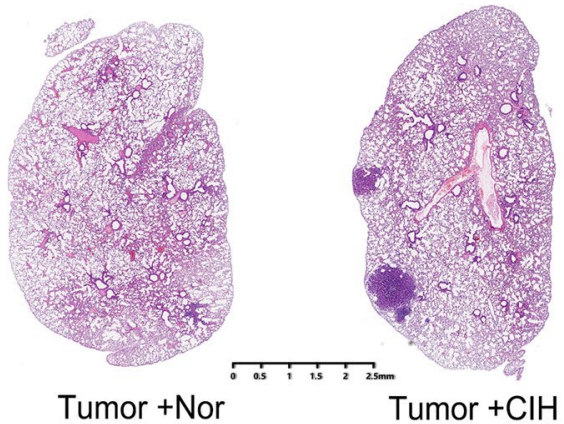

f HIF-10



$$
\text { CD44 }
$$
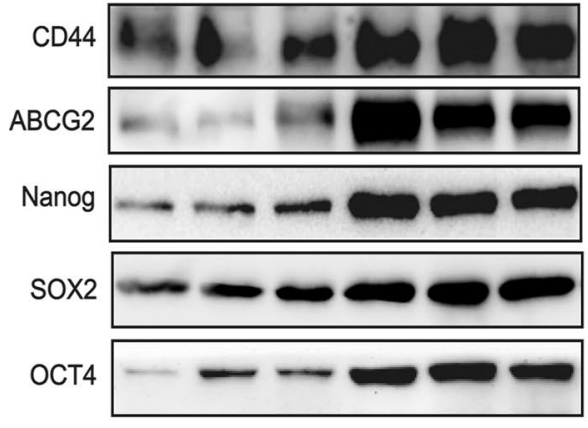

GAPDH

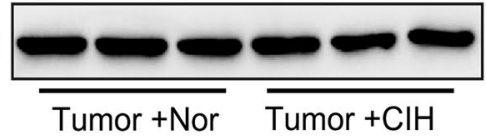

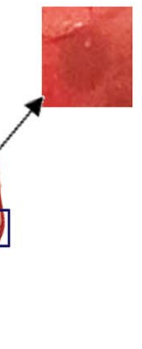

d $\quad$ Tumor+Nor $\leftarrow$ Tumor $+\mathrm{ClH}$
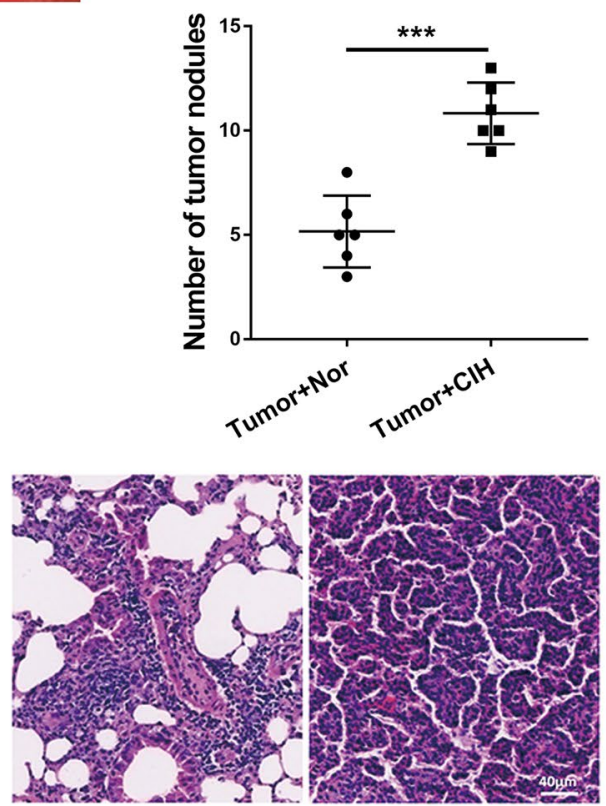

Tumor +Nor

Tumor $+\mathrm{ClH}$

g

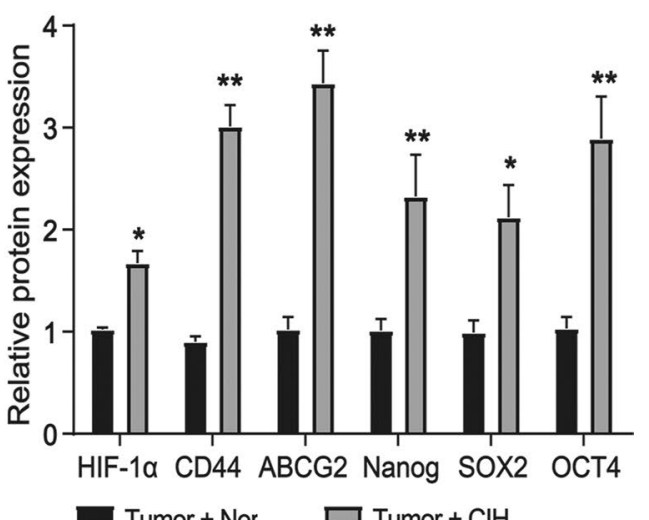


chamber attached to an external $\mathrm{O}_{2}-\mathrm{CO}_{2}$ computerdriven servo controller (Biospherix, Lacona, NY), where the $\mathrm{O}_{2}$ concentration was altered between 0 and $21 \%$ every 30 min by injecting $\mathrm{N}_{2}$ or $\mathrm{O}_{2}$ with $5 \% \mathrm{CO}_{2}$. The dissolved $\mathrm{O}_{2}$ inside the culture medium was monitored by a laser $\mathrm{O}_{2}$ probe (Biospherix) and the $\mathrm{CIH}$ reached 5\% $\mathrm{O}_{2}$ and $21 \% \mathrm{O}_{2}$ as hypoxic and normoxic values according to the sensing of the cells. Normal air conditions corresponded to $21 \% \mathrm{O}_{2}$ and $5 \% \mathrm{CO}_{2}$. Human Bach1 or control (Genechem, Shanghai, China) shRNA were transfected into A549 and SPC cells with Lipofectamine 2000 (Invitrogen) according to the manufacturer's instructions.

\section{Immunohistochemistry}

After flushing, the lower lobe of each lung was stored at $-80{ }^{\circ} \mathrm{C}$ for RNA and proteomic analyses. The upper lobe of the lung was fixed by perfusion with $3.8 \%$ paraformaldehyde and embedded in paraffin. Tissue sections $(4 \mu \mathrm{m})$ were stained with hematoxylin and eosin (HE) for routine histological analysis.

\section{Cell viability and Edu assy}

Cells were plated onto 96-well plates in triplicate at a density of $1 \times 10^{3}$ cells per well and allowed to adhere overnight in 1640 medium. Cells were cultured under Nor or $\mathrm{CIH}$ conditions for different time points. Before detection, $10 \mu \mathrm{M} /$ well of CCK8 was added and incubated for $2 \mathrm{~h}$. The absorbance was measured at $570 \mathrm{~nm}$ using a microplate spectrophotometer. Edu (BeyoClick ${ }^{\mathrm{TM}}$ EdU, Beyotime) staining was used and performed following the manufacturer's instructions for labeling of the nucleus of dividing cells. The cells were treated with $10 \mu \mathrm{M}$ EdU. After $2 \mathrm{~h}$, the cells were fixed and incubated with DAPI. Then, the cells were observed on a laser scanning microscope.

\section{Colony formation assay}

A549 and SPCA1 were seeded in six-well plates at a density of 800 cells/well. Cells were cultured under Nor or $\mathrm{CIH}$ conditions. Two weeks later, cell colonies were fixed and stained with crystal violet. A colony was defined as 50 cells.

\section{Flow cytometric analysis}

A549 and SPCA1 were seeded in 12-well plates at a proper concentration and cultured under Nor or $\mathrm{CIH}$ condition for $48 \mathrm{~h}$. At the end of $\mathrm{CIH}$ cycles, cells were harvested, filtration and centrifugation, and FITC-labeled anti-CD44 (555478) and APC-labeled anti-CD133 (53276) (Cell Signaling Technologies, USA) were used for surface staining. The adherent cells were treated with mitoSOX ${ }^{\mathrm{TM}}$ red mitochondrial superoxide indicator (Invitrogen $^{\mathrm{TM}}$ ) at a final concentration of $5 \mu \mathrm{M}$ for $10 \mathrm{~min}$ at
Table 1 Primers used for real-time PCR

\begin{tabular}{lll}
\hline Genes & Forward $\left(\mathbf{5}^{\prime} \mathbf{-} \mathbf{3}^{\prime}\right)$ & Reverse $\mathbf{( 5}^{\prime} \mathbf{-} \mathbf{3}^{\prime} \mathbf{)}$ \\
\hline GAPDH & GCACCGTCAAGGCTGAGAAC & TGGTGAAGACGCCAGTGGA \\
CD44 & GCATTGCAGTCAACAGTC & CCTTGTTCACCAAATGCACCA \\
Sox2 & GAAGA & TAGGTCTG CGAGCTGGTCAT \\
Nanog & GACAGTTACGCGCACATGAA & ACACAGCTGGGTGAAGAGA \\
Oct4 & GTGATTTTGGGCCTGA AGA & CACACTCGGACCACATCCTT \\
CD133 & GGTATTCAGCCAAACGACCA & AAAGG GCAGTTGACGGAAC \\
& GAACAGGGCTACTCGCAAAG & \\
\hline
\end{tabular}

$37{ }^{\circ} \mathrm{C}$ and washed with PBS three times. Then the cells were harvested, filtration and centrifugation. Cells were detected by the quantitation of fluorescence intensity by flow cytometry. All data were analyzed with FlowJo software (Tree Star Inc., San Carlos, CA).

\section{Sphere formation assay}

Cells were indicated with $10 \mathrm{ng} / \mathrm{mL}$ of human recombinant basic fibroblast growth factor (R\&D Systems, Minneapolis, MN) and $20 \mathrm{ng} / \mathrm{mL}$ of epidermal growth factor (R\&D Systems) in serum-free Dulbecco's Modified Eagle's Medium-F12 (Gibco) medium. Spheres were observed using a microscope (Olympus, Tokyo, Japan).

\section{Western blot analysis and quantitative real-time PCR}

Cell and tissue lysates were prepared and performed as previously described. Briefly, membranes were blocked with 5\% nonfat dry milk in TBST for $1 \mathrm{~h}$ and incubated overnight at $4{ }^{\circ} \mathrm{C}$ with primary Abs against CD133 (64326S), CD44 (37259S), Oct-4 (2750S), Nanog (4903S), Sox2 (14962S), ABCG2 (42078S), Bach1 (4578), HIF-1 $\alpha$ (14179), and GADPH (5174) (purchased from Cell Signaling Technologies). The membranes were incubated with an anti-rabbit horseradish peroxidase-conjugated secondary Ab (Cell Signaling Technologies), and protein bands were detected by chemiluminescence using Immobilon Forte Western HRP substrate (Millipore WBLUF0500). Total RNA was extracted from A549 or SPCA1 using TRIzol reagent (Takara Bio, Shiga, Japan). cDNA was synthesized from the isolated RNA, and quantitative PCR was performed according to the manufacturer's instructions. This quantitative assay was performed using an SYBR QPCR kit (Toyobo, Osaka, Japan). The primer sequences used for PCR were provided in Table 1. Densitometry was performed using ImageJ software (NIH, Bethesda, MD). All experiments were performed in triplicate.

\section{Statistical analyses}

For in vitro experiments, data represent at least three biological replicates performed with a minimum of duplicate technical replicates unless indicated otherwise. The two-tailed, unpaired Student's t-test was used 
to determine statistical significance for all experiments unless indicated otherwise. Statistical significance was denoted as follows: ${ }^{*} P<0.05,{ }^{* *} P<0.01,{ }^{* * *} P<0.001$, ***:* $P<0.0001$. Data are shown as mean \pm SEM unless indicated otherwise.

\section{Results}

\section{ClH promoted carcinogen-induced Tumor growth}

To explore the effect of $\mathrm{CIH}$ on lung carcinogenesis, an orthothopic lung tumor model was established in WT mice by induction with a cumulative high dose of urethane injection. After six months, the mice were randomly cultured under normoxia (Nor) or $\mathrm{CIH}$ condition as we described in Methods (Fig. 1a). We observed that Tumor $+\mathrm{CIH}$ groups exhibited lower survival rates and accelerated tumor growth than Tumor + Nor groups (Fig. 1b). The lungs of mice in the Tumor $+\mathrm{CIH}$ group contained a greater number and larger metastases compared to Tumor + Nor group (Fig. 1c-e). CD44, ABCG2, Nanog, SOX2, and Oct4 were identified as important stem-cell transcription factors or markers involved in maintaining the CSC-like phenotypes in many kinds of cancer. To verify the influence of $\mathrm{CIH}$ on CSC-like properties of lung cancer, the protein levels of these markers were detected by western blot tests in cancer nodules from Tumor + Nor and Tumor $+\mathrm{CIH}$ groups. As shown in Fig. $1 \mathrm{f}$ and $\mathrm{g}$, the expression levels of CD44, SOX2, Nanog, Oct4, and ABCG2 in lung cancer nodules from Tumor $+\mathrm{CIH}$ groups were significantly upregulated compared with the lung cancer tissues from Tumor + Nor mice. The above results indicated that $\mathrm{CIH}$ promoted stemness in lung cancer.

2. $\mathrm{CIH}$ promoted lung cancer cell proliferation

Next, we employed A549 and SPCA1, two commonly used non-small cell lung cancer (NSCLC) lines to further validate the effect of $\mathrm{CIH}$ on the proliferation of NSCLC cells. A549 or SPCA1 were cultured under $\mathrm{CIH}$ or Nor conditions for $24,48,72,96 \mathrm{~h}$, and the proliferation of cells was tested by the CCK- 8 assay at different time points. As presented by optical density, A549 or SPCA1 cultured under CIH conditions exhibited significantly increased cell validation compared with the cells cultured under Nor conditions (Fig. 2a and b). Additionally, $\mathrm{CIH}$ exposure statistically increased the percentage of Edu-positive cells (Fig. 2c-e). The colony-forming ability of cells was also enhanced by $\mathrm{CIH}$ exposure validated by plate cloning test (Fig. 2f-h).

3. CIH induced CSC-like phenotypes in lung cancer cells

To further determine the effect of $\mathrm{CIH}$ on the formation of CSCs in NSCLCs, a sphere-forming assay was performed to detect the capacity of CSC-like cell self-renewal in our study (Fig. 3a). We found that $\mathrm{CIH}$ promoted the formation of spheres. Meanwhile, CD44, CD133, Nanog, Oct4, and SOX2 mRNA were increased in $\mathrm{CIH}$-treatment NSCLC cells validated by RT-PCR (Fig. 3b). As CD133 and CD44 are two important CSC surface markers in several types of cancer, $\mathrm{CIH}$ exposure significantly enhanced the percentage of $\mathrm{CD} 44^{+} \mathrm{CD} 133^{+}$subsets in NSCLC cells evidenced by flowmetry analysis (Fig. 3c).

4. $\mathrm{CIH}$ promoted mtROS accumulation and Bach1 expression in vitro and in vivo

Many studies have identified ROS as an important regulator in CSCs, and mtROS is a major source of ROS. Though the role of ROS in the cancer process is controversial, we found that $\mathrm{CIH}$ notably promoted the levels of mtROS in NSCLC cells in our study (Fig. $4 \mathrm{a}-\mathrm{C}$ ). Bach1 is a transcriptor repressing the expression of the antioxidant enzyme. We previously demonstrated that Bach1 induced CD44 expression to promote CSC-like properties in NSCLCs (have not been published). To further evaluate the role of Bach1 in OSA-deteriorated lung cancers, we compared the expression levels of Bach1 in lung cancer nodules and NSCLC cells between $\mathrm{CIH}$ and Nor conditions. As shown in Fig. $5 \mathrm{a}$ and b, Bach1 was obviously increased in lung cancer nodules from Tumor $+\mathrm{CIH}$ mice compared with those from Tumor + Nor mice. Furthermore, $\mathrm{CIH}$-treated A549 and SPCA1 presented higher expression levels of Bach1 than Nor treated cells. Nanog, SOX2, and OCT4 were also determined in $\mathrm{CIH}$ and Nor treated cells, and the same tendency was observed (Fig. $5 \mathrm{c}-$ e).

5. Bach1 knockdown attenuated $\mathrm{CIH}$-induced mtROS accumulation and CSC-like phenotypes

To further determine the role of Bach1 in CIH-deteriorated lung cancer, Bach1 shRNA was used in the following experiments. After treated with Bach1 shRNA, the effect of $\mathrm{CIH}$ on CSC-like phenotype induction in NSCLC cells was partly abolished evidenced by a decreased percentage of $\mathrm{CD} 44^{+} \mathrm{CD} 133^{+} \mathrm{A} 549$ or SPCA1 
a

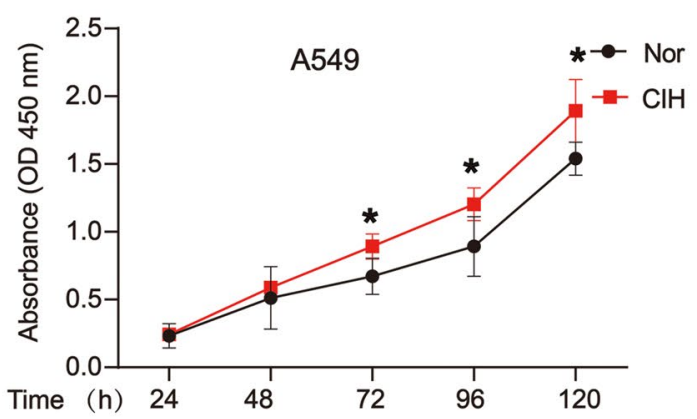

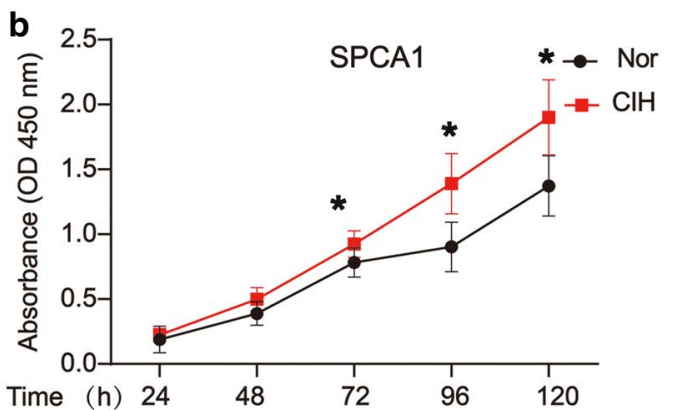

C $\mathrm{A} 549$
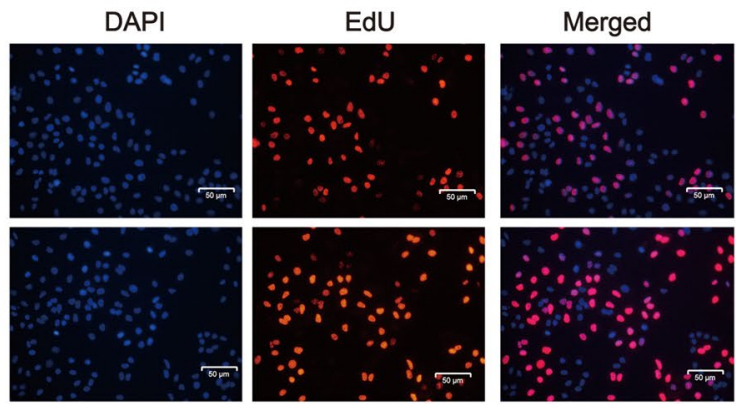

d SPCA1


DAPI

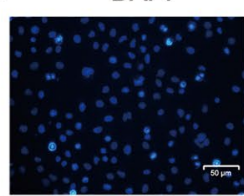

EdU

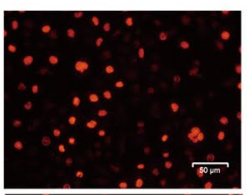

Merged

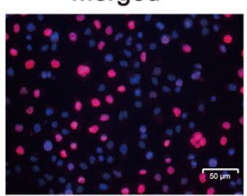

$\mathrm{ClH}$
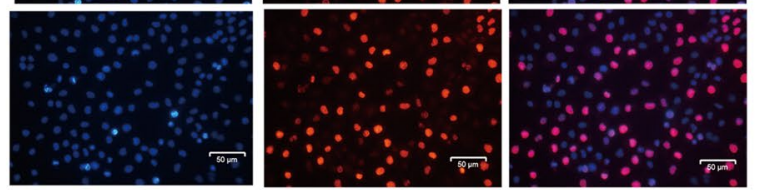

$\mathbf{f}$

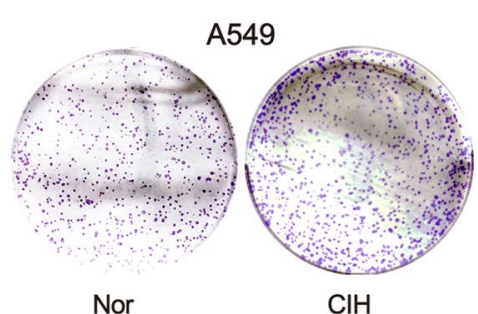

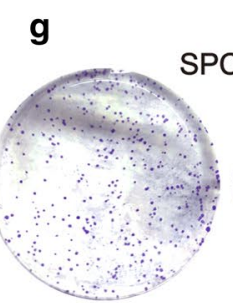

Nor
SPCA1

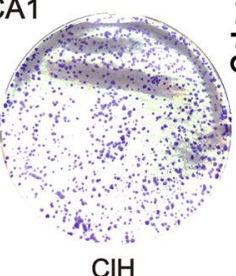

$\mathrm{ClH}$

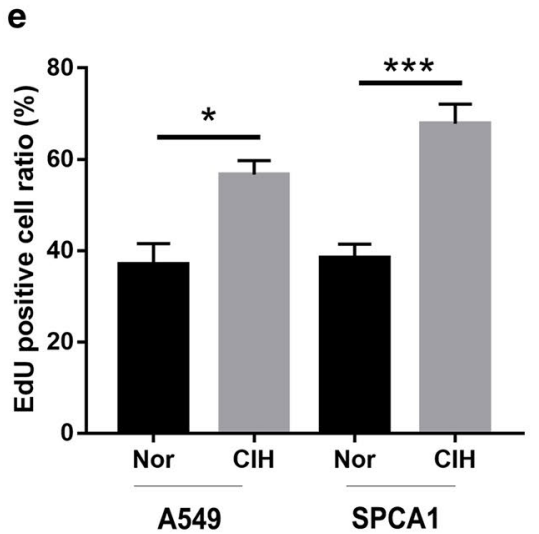

h

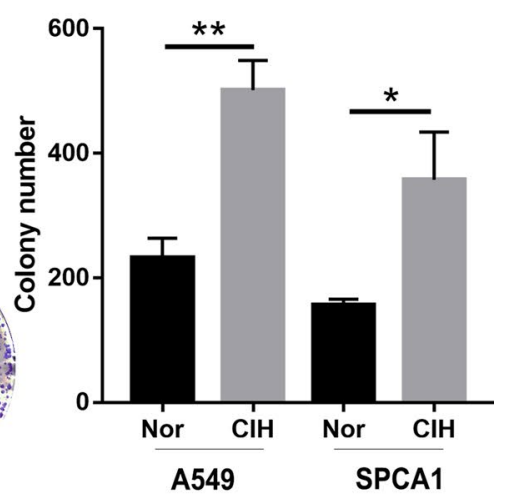

A549

Fig. $2 \mathrm{CIH}$ promoted lung cancer cell proliferation. Cell validations of A549 (a) and SPCA1 (b) were detected by CCK-8 assay after exposure to Nor or CIH for 24, 48, 72, and 96 h. Cell proliferation of A549 (c) or SPCA1 (d) after 48-h Nor or CIH exposure was assessed using Edu assay. e The percentage of Edu positive cells in A549 or SPCA1 was analyzed and illustrated. $\mathbf{f}, \mathbf{g}$ Assessment of cancer genericity was performed by colony formation analysis after $\mathrm{ClH}$ treatment. $\mathbf{h}$ The number of colonies was measured and illustrated. Error bars represent the mean \pm SEM of at least triplicate experiments. ${ }^{*} P<0.05,{ }^{*} P<0.01$. CIH chronic intermittent hypoxia

\section{(See figure on next page.)}

Fig. $3 \mathrm{CIH}$ promoted CSC-like properties in NSCLC cells. a Microscopic observation of NSCLC cells. A549 and SPCA1 spheroids were obtained and then cultured under Nor or $\mathrm{CIH}$ conditions for 24 h. b qRCP analyses in triplicate of CD44, Sox2, Nanog, Oct4, and CD133 in NSCLC cells. Adherent A549 and SPCA1 were treated with $24 \mathrm{~h}$-Nor or $\mathrm{ClH}$ exposure. GADPH expression served as an internal control. c Flow cytometry analyses of the percentage of $\mathrm{CD}_{4} 4^{+} \mathrm{CD} 133^{+}$cells in $\mathrm{A} 549$ or SPCA1 populations. Error bars represent the mean $\pm \mathrm{SEM}$ of at least triplicate experiments. ${ }^{*} P<0.05$, ${ }^{*} P<0.01$. CIH chronic intermittent hypoxia, CSC cancer stem cell 

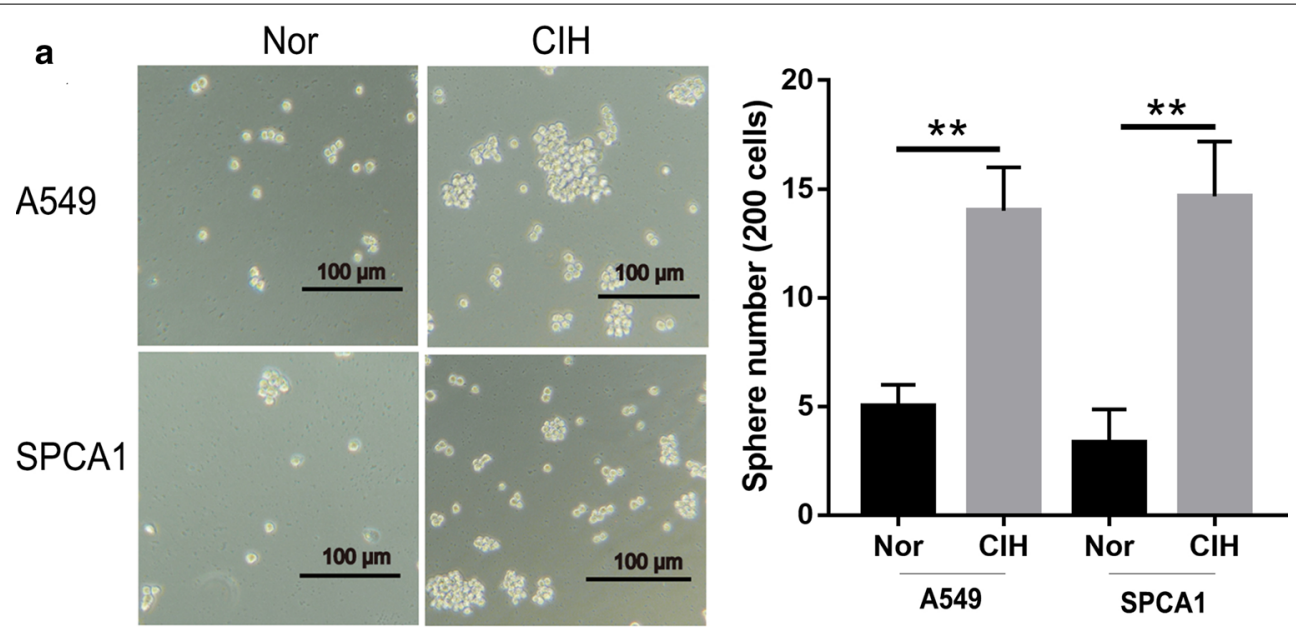

b
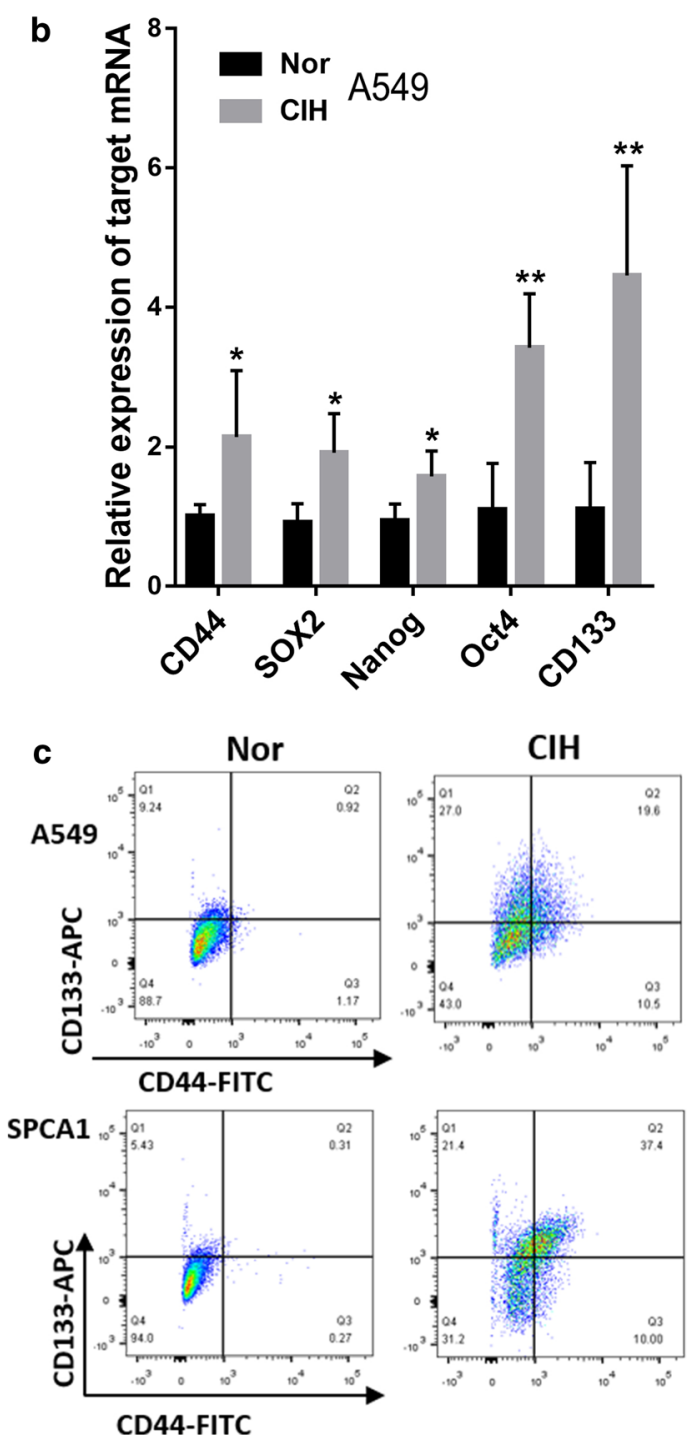

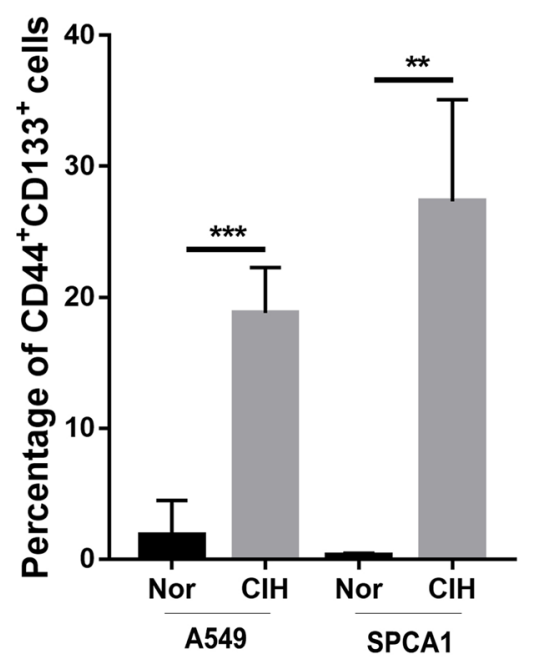



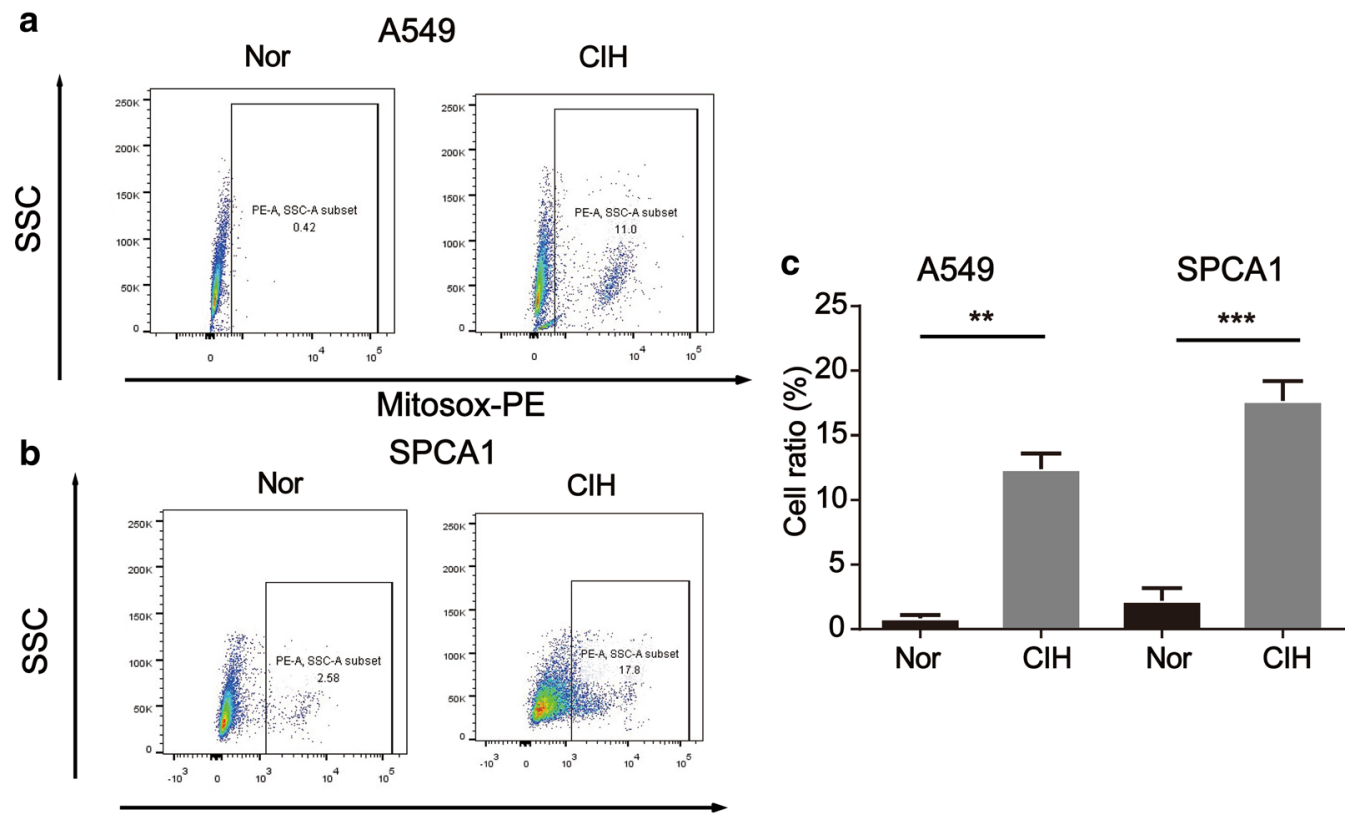

\section{Mitosox-PE}

Fig. $4 \mathrm{CIH}$ induces mitochondrial ROS accumulation in NSCLC cells. Flow cytometric analysis of A549 (a) or SPCA1 (b) treated with MitoSOX after $\mathrm{ClH}$ exposure for $48 \mathrm{hrs}$ is shown. c Quantitative analysis of MitoSOX-positive cells is shown. All data are presented as the mean $\pm S E M$. ${ }^{*} P<0.05$, ${ }^{* *} P<0.01$ and ${ }^{* *} P<0.001$ compared with the control group. Every experiment was repeated at least three times. CIH chronic intermittent hypoxia

in total cells (Fig. 6a-c). Meanwhile, $\mathrm{CIH}$ also failed to further induce mtROS accumulation in NSCLC cells co-treated with Bach1 shRNA (Fig. 6d-f). Our collective data supported the requirement of Bach1 for mtROS accumulation and the maintenance of CSC property in NSCLCs.

\section{Discussion}

OSA is increasingly recognized as an important promotor in the process of lung carcinoma. In this study, our data show that murine lung cancer exposed to $\mathrm{CIH}$ exhibit increased tumor growth. The more deteriorated lung cancer associated with $\mathrm{CIH}$ can be partly explained by mtROS accumulation and increased Bach1 expression, resulting in enhanced CSC-like property. To our knowledge, this is the first study uncovering the relationship between OSA and lung CSCs, as well as the possible mechanism for Bach1 involved in $\mathrm{CIH}$-deteriorating lung cancer. Our findings provide a useful model and biological hypothesis to the adverse cancer outcomes reported in lung cancer patients with OSA.

Data from the current study demonstrated for the first time that $\mathrm{CIH}$ induces CSC-like property in lung cancer. Despite advances in anti-cancer therapies such as targeted therapies and immunotherapy, lung cancer is still the world's leading cause of cancer mortality with about a $15 \%$ five-year survival rate. Furthermore, an increased risk of death and notably reduction of progression-free survival (PFS) were observed in lung cancer patients with severe OSA [23, 24]. Tumor resistance reduces the efficacy of current therapies resulting in relapse, progression, and subsequent patients' death [25]. CSCs referred to as tumor-initiating cells, are increasingly recognized as a key factor in tumor progression, metastasis, and drug resistance $[13,15]$. In this study, we established an orthotopic mouse model of primary lung cancer and cultured the mice under $\mathrm{CIH}$ conditions to mimic the process in the comorbidity of primary lung cancer and OSA. In line with previous studies [26], we observed that $\mathrm{CIH}$ accelerated the development of lung cancer. Additionally, $\mathrm{CIH}$ promoted CSC-like properties in vitro and in vivo. Considering the role of CSCs in lung cancer, our research may partly explain the adverse effect of OSA on lung cancer. However, further clinical researches are still needed to verify whether tumor resistance and poor treatment are directly related to OSA.

The possible underlying mechanisms that OSA-like $\mathrm{CIH}$ results in facilitating the development and progression of tumors have been proposed in several investigations. Immune response $[26,27]$ and hypoxiarelated factors such as HIF-1 $\alpha$ and ROS [23] were the most commonly explored mechanisms in these studies. Bach1 referred to as a transcriptional factor, plays a regulatory role in ROS by inhibiting the transcription 


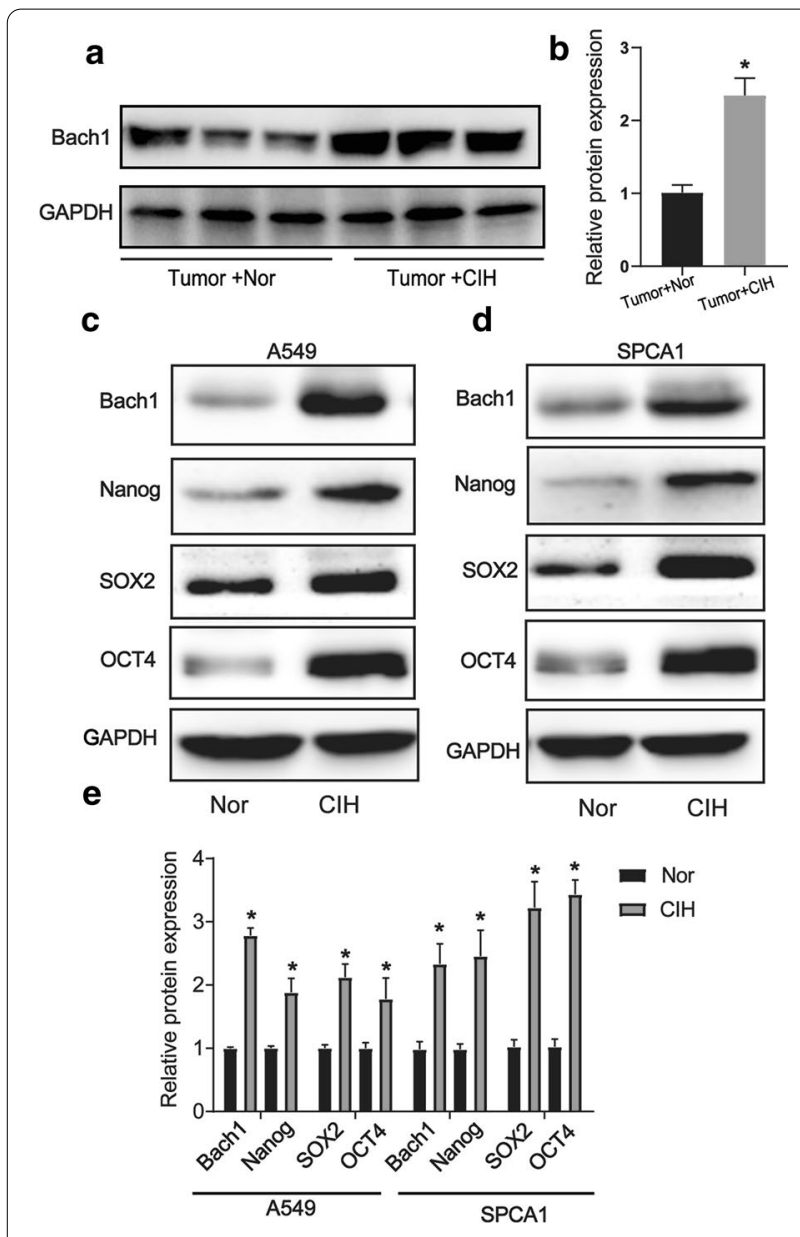

Fig. $5 \mathrm{ClH}$ increased Bach1 expression and CSC-like property. a The protein expression of Bach1 in lung cancer nodules from Tumor + Nor or Tumor $+\mathrm{ClH}$ mice by Western blot analysis. b Quantification of relative protein expression was performed by densitometric analysis, and GADPH acted as an internal control. The protein expression of Bach1, Nanog, SOX2, and OCT4 in A549 (c) or SPCA1 (d) after $\mathrm{ClH}$ exposure for $48 \mathrm{~h}$ by Western blot analysis. e Quantification of relative protein expression was performed by densitometric analysis, and GADPH acted as an internal control. All data are presented as the mean \pm SEM. ${ }^{*} P<0.05$ compared with the control group. Every experiment was repeated at least three times. $\mathrm{ClH}$ chronic intermittent hypoxia, CSC cancer stem cell of ROS-related genes, such as heme oxygenase-1 (HO1) [28] and NADPH quinone oxidoreductase 1 (NQO1) [29]. Moreover, Bach1 was also involved in cell cycle [30], immunity [31], and has been shown to suppress angiogenesis [32] and promoted cancer metastasis, such as breast [33], ovarian [34], and lung cancer[35]. In this study, we found that the expression level of Bach1 was increased in lung cancer nodules from $\mathrm{CIH}$-treated mice and NSCLC cells exposed to CIH conditions accompanied by an increased mtROS. Moreover, Bach1 knockdown decreased the expression of mtROS. Growing evidence has also shown that inhibition of Bach1 alleviates oxidative stress [30]. Based on these previous studies, we found that $\mathrm{CIH}$ can accelerate mtROS production by promoting Bach1 expression.

Our results also indicated that the increased expression of Bach1 induced by $\mathrm{CIH}$ exposure was accompanied by increased CSC-related translators such as Nanog, SOX2, ABCG2, Oct4, and markers including CD44 and CD133. Furthermore, the increased CSC-like properties induced by $\mathrm{CIH}$ were repressed by Bach1 knockdown. Though the effects of Bach1 on maintaining CSC-like property were little reported, our observation is consistent with previous reports that Bach1 can regulate self-renewal and stabilize Nanog, SOX2, and Oct4 in human embryonic stem cells [36]. Additionally, our previous study found that Bach1 can promote lung CSC phenotype by inducing CD44 expression (have not been published). This study has some limitations: there lacks clinical evidence that lung cancer tissues from NSCLC patients with OSA present a higher Bach1 expression and lung CSC properties than those from NSCLC patients without OSA. Also, the regulatory mechanism of Bach1 on stemness in lung CSC still needs further research.

\section{Conclusions}

In conclusion, our findings present a promotor role for $\mathrm{CIH}$ in lung cancer development. Besides, the results uncover that $\mathrm{CIH}$ induces the lung $\mathrm{CSC}$-like properties 
a

A549


b
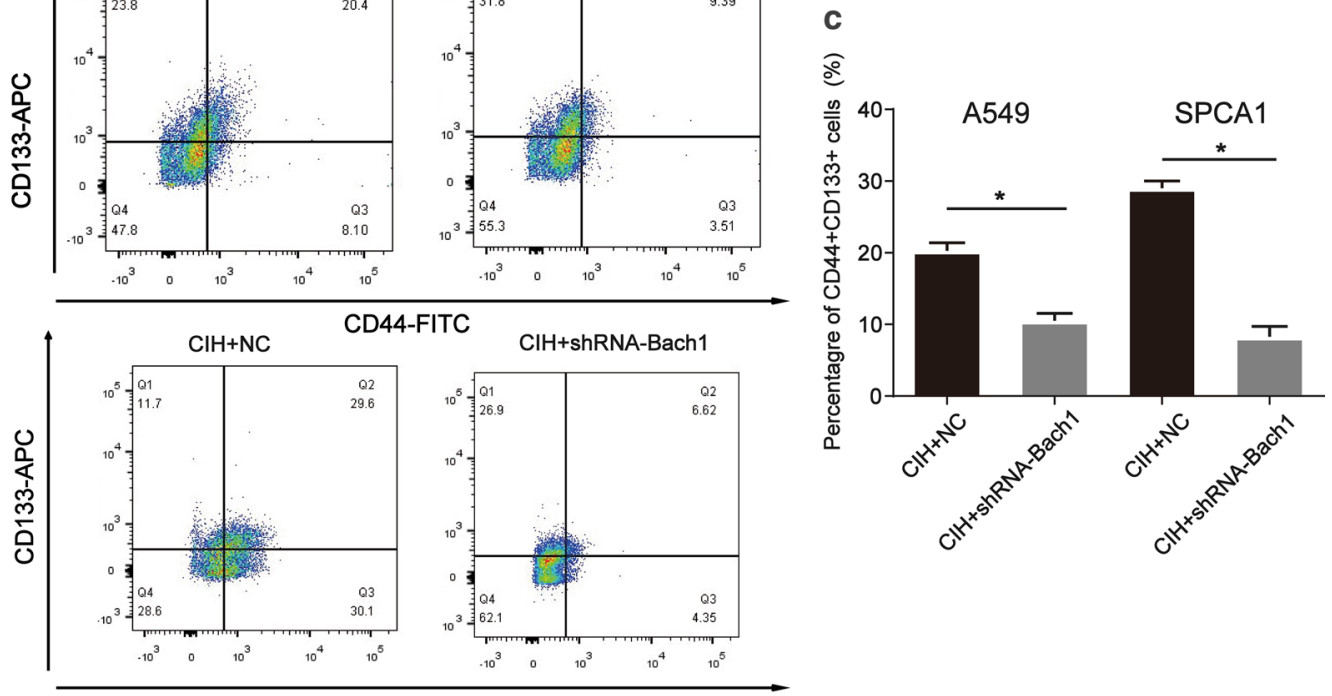

SPCA1

d

CD44-FITC

A549

$\mathrm{ClH}+\mathrm{NC}$
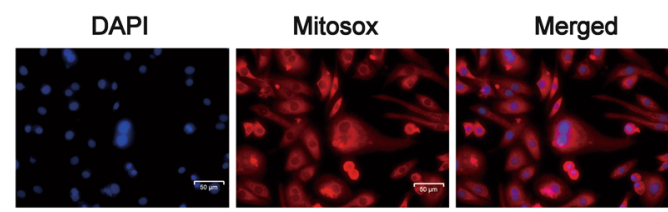

CIH+shRNA-Bach1
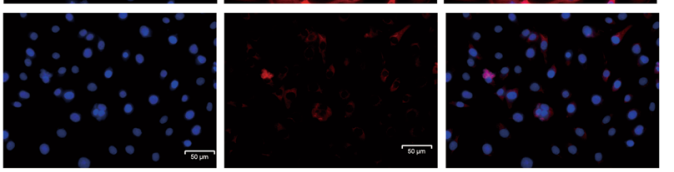

e

SPCA1

DAPI

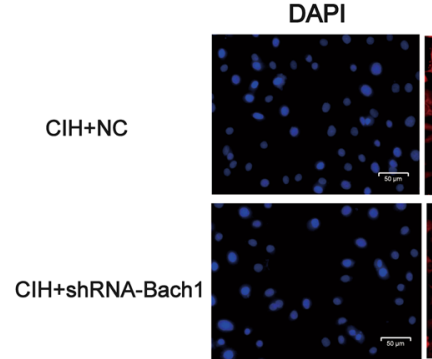

Mitosox
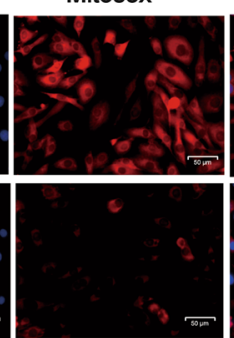

Merged

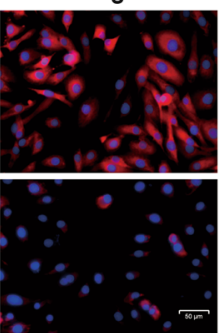

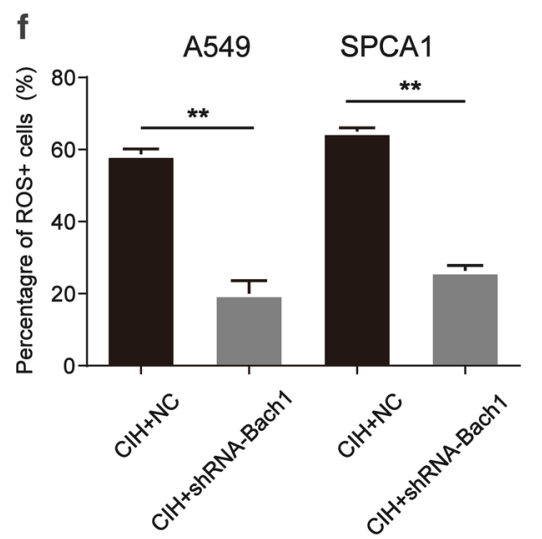

Fig. 6 Knockdown of Bach1 decreased the stemness and mitochondrial ROS accumulation in CIH-treated NSCLCs. Bach1 shRNA or parental negative control (NC) was transfected into A549 or SPCA1. Then the cells were cultured under ClH conditions for $48 \mathrm{hrs}$. Flow cytometry analyses of $\mathrm{CD}_{4} 4^{+} \mathrm{CD}_{13}{ }^{+}$cells in Nor or ClH-treated A549 (a) or SPCA1 (b). c The percentage of CD44 ${ }^{+}$CD133 ${ }^{+}$cells in Nor or ClH-treated cells was measured and illustrated. Fluorescence microscopy analysis for localization of mtROS production in A549 (d) and SPCA1 (e). Nuclei was stained with Hoechst (blue), mitochondria ROS were stained with MitoSOX-red. The merged panels showed the MitoSOX-red positive cells in total cells. fThe percentage of MitoSOX positive cells was measured and illustrated. All experiments were performed in triplicate, and data are presented as mean \pm SEM. ${ }^{*} P<0.05$, ${ }^{* *} P<0.01$ compared with the control group 
in a Bach1-dependent way. These observations suggest that Bach1 may serve as a unique strategy for patients with OSA-related lung cancer, but more work is needed to fully verify the role of Bach1 in OSA-deteriorated lung cancer.

\section{Abbreviations}

OSA: Obstructive sleep apnea; CSCs: Cancer stem cells; $\mathrm{ClH}$ : Chronic intermittent hypoxia; Bach1: Transcription factor BTB and CNC homology 1; mtROS: Mitochondrial ROS; HE: Hematoxylin and eosin; Nor: Normoxia; NSCLC: Non-small cell lung cancer; HO-1: Heme oxygenase-1; NQO1: NADPH quinone oxidoreductase 1.

\section{Acknowledgements}

We would like to thank the researchers for their contributions.

\section{Authors' contributions}

SH, XZ and PJ performed most of the experiments. ZL, SH and PJ raised animals and performed $\mathrm{CIH}$ exposure. XW conducted some experiments. $\mathrm{SH}$, $P J, S L$ and $L J$ designed the project and edited the manuscript. All authors read and approved the final manuscript.

\section{Funding}

This study was supported by the National Key Research and Development Program of China (No. 2018YFC1313600), the National Natural Science Foundation of China (No. 82070094), Shanghai Rising-Star Program (No. 19YF1407200), the Major Project Matching Funding Project of Shanghai Science and Technology (No. 198012309).

\section{Availability of data and materials}

The data that support the findings of this study are available from the corresponding author upon reasonable request.

\section{Ethics approval and consent to participate}

This study was approved by Zhongshan Hospital Institutional Animal Care and Use Committee

\section{Consent for publication}

Not applicable.

\section{Competing interests}

The authors declare that they have no conflict of interest.

\section{Author details}

1 Department of Pulmonary Medicine, Zhongshan Hospital, Fudan University, 180 Fenglin Road, Shanghai 200032, China. ${ }^{2}$ Clinical Center for Sleep Breathing Disorder and Snoring, Zhongshan Hospital, Fudan University, Shanghai 200032, China.

Received: 18 December 2020 Accepted: 7 February 2021

Published online: 17 February 2021

\section{References}

1. Patel SR. Obstructive sleep apnea. Ann Intern Med. 2019;171:itc81-96.

2. Gottlieb DJ, Punjabi NM. Diagnosis and management of obstructive sleep apnea: a review. JAMA. 2020;323:1389-400.

3. Choi JH, Lee JY, Han KD, Lim YC, Cho JH. Association between obstructive sleep apnoea and breast cancer: The Korean National Health Insurance Service Data 2007-2014. Sci Rep. 2019;9:19044.

4. Martinez-Garcia MA, Campos-Rodriguez F, Almendros I, Garcia-Rio F, Sanchez-de-la-Torre M, Farre R, Gozal D. Cancer and sleep apnea: cutaneous melanoma as a case study. Am J Respir Crit Care Med. 2019;200:1345-53.

5. Santamaria-Martos F, Benítez I, Girón C, Barbé F, Martínez-García MA, Hernández L, Montserrat JM, Nagore E, Martorell A, Campos-Rodriguez $\mathrm{F}$, et al. Biomarkers of carcinogenesis and tumour growth in patients with cutaneous melanoma and obstructive sleep apnoea. Eur Respir J. 2018. https://doi.org/10.1183/13993003.01885-2017.

6. Vilaseca A, Campillo N, Torres M, Musquera M, Gozal D, Montserrat JM, Alcaraz A, Touijer KA, Farré R, Almendros I. Intermittent hypoxia increases kidney tumor vascularization in a murine model of sleep apnea. PLoS ONE. 2017;12:e0179444.

7. Gozal D, Ham SA, Mokhlesi B. Sleep apnea and cancer: analysis of a nationwide population sample. Sleep. 2016;39:1493-500.

8. Justeau G, Gervès-Pinquié C, Le Vaillant M, Trzepizur W, Meslier N, Goupil F, Pigeanne T, Launois S, Leclair-Visonneau L, Masson P, et al. Association between nocturnal hypoxemia and cancer incidence in patients investigated for OSA: data from a large multicenter french cohort. Chest. 2020. https://doi.org/10.1016/j.chest.2020.06.055.

9. Bade BC, Dela Cruz CS. Lung cancer 2020: epidemiology, etiology, and prevention. Clin Chest Med. 2020;41:1-24.

10. Koh Y, Han J, Haam SJP. Expression of PD-L1, cancer stem cell and epithelial-mesenchymal transition phenotype in non-small cell lung cancer. Pathology. 2021;53:239-46.

11. French $R$, Pauklin S. Epigenetic regulation of cancer stem cell formation and maintenance. IJC. 2020. https://doi.org/10.1002/ijc.33398.

12. Oshimori N. Cancer stem cells and their niche in the progression of squamous cell carcinoma. Cancer Sci. 2020;111:3985-92.

13. Heng W, Gosens R, Kruyt FJ. Lung cancer stem cells: origin, features, maintenance mechanisms and therapeutic targeting. Biochem Pharmacol. 2019;160:121-33.

14. Alguacil-Núñez C, Ferrer-Ortiz I, García-Verdú E, López-Pirez P, LlorenteCortijo I, Sainz BJ. Current perspectives on the crosstalk between lung cancer stem cells and cancer-associated fibroblasts. Crit Rev Oncol Hematol. 2018;125:102-10.

15. Dzobo K, Senthebane D, Ganz C, Thomford N, Wonkam A, Dandara CJ. Advances in therapeutic targeting of cancer stem cells within the tumor microenvironment: an updated review. Cells. 2020. https://doi. org/10.3390/cells9081896.

16. Sun X, Lv X, Yan Y, Zhao Y, Ma R, He M, Wei MJB. Hypoxia-mediated cancer stem cell resistance and targeted therapy. Biomed Pharmacother. 2020:130:110623

17. Le Gal K, Ibrahim MX, Wiel C, Sayin VI, Akula MK, Karlsson C, Dalin MG, Akyürek LM, Lindahl P, Nilsson J, Bergo MO. Antioxidants can increase melanoma metastasis in mice. Sci Transl Med. 2015;7:308re308.

18. Klein EA, Thompson IM, Tangen CM, Crowley JJ, Lucia MS, Goodman PJ, Minasian LM, Ford LG, Parnes HL, Gaziano JM, et al. Vitamin E and the risk of prostate cancer: the selenium and Vitamin E Cancer Prevention Trial (SELECT). JAMA. 2011;306:1549-56.

19. van Zandwijk N, Dalesio O, Pastorino $U$, de Vries N, van Tinteren $H$. EUROSCAN, a randomized trial of vitamin A and $\mathrm{N}$-acetylcysteine in patients with head and neck cancer or lung cancer. For the EUropean Organization for Research and Treatment of Cancer Head and Neck and Lung Cancer Cooperative Groups. J Natl Cancer Inst. 2000:92:977-86

20. Zhang X, Guo J, Wei X, Niu C, Jia M, Li Q, Meng D. Bach1: function, regulation, and involvement in disease. Oxid Med Cell Longev. 2018;2018:1347969.

21. Song JQ, Jiang LY, Fu CP, Wu X, Liu ZL, Xie L, Wu XD, Hao SY, Li SQ. Heterozygous SOD2 deletion deteriorated chronic intermittent hypoxiainduced lung inflammation and vascular remodeling through mtROSNLRP3 signaling pathway. Acta Pharmacol Sin. 2020;41:1197-207.

22. Hao S, Jiang L, Fu C, Wu X, Liu Z, Song J, Lu H, Wu X, Li S. 2-Methoxyestradiol attenuates chronic-intermittent-hypoxia-induced pulmonary hypertension through regulating microRNA-223. J Cell Physiol. 2019:234:6324-35.

23. Huang HY, Shih-Wei L, Chuang LP, Wang CL, Sun MH, Li HY, Chang CJ, Chang SC, Yang CT, Chen NH. Severe obstructive sleep apnea associated with higher risk of mortality in stage III and IV lung cancer. J Clin Sleep Med. 2020. https://doi.org/10.5664/jcsm.8432.

24. Pérez-Warnisher MT, Cabezas E, Troncoso MF, GómezT, Melchor R, Pinillos EJ, El Hachem A, Gotera C, Rodriguez P, Mahíllo I, et al. Sleep disordered breathing and nocturnal hypoxemia are very prevalent in a lung cancer screening population and may condition lung cancer screening findings: results of the prospective Sleep Apnea In Lung Cancer Screening (SAILS) study. Sleep Med. 2019;54:181-6. 
25. Clara JA, Monge C, Yang Y, Takebe N. Targeting signalling pathways and the immune microenvironment of cancer stem cells-a clinical update. Nat Rev Clin Oncol. 2020;17:204-32.

26. Almendros I, Wang Y, Becker L, Lennon F, Zheng J, Coats B, Schoenfelt K, Carreras A, Hakim F, Zhang S, et al. Intermittent hypoxia-induced changes in tumor-associated macrophages and tumor malignancy in a mouse model of sleep apnea. Am J Respir Crit Care Med. 2014;189:593-601.

27. Liu Y, Lao M, Chen J, Lu M, Luo S, Ou Q, Luo Z, Yuan P, Chen J, Ye G, Gao XJ. Short-term prognostic effects of circulating regulatory T-Cell suppressive function and vascular endothelial growth factor level in patients with non-small cell lung cancer and obstructive sleep apnea. Sleep Med. 2020;70:88-96.

28. Sun J, Hoshino H, Takaku K, Nakajima O, Muto A, Suzuki H, Tashiro S, Takahashi S, Shibahara S, Alam J, et al. Hemoprotein Bach1 regulates enhancer availability of heme oxygenase-1 gene. Embo J. 2002;21:5216-24.

29. Dhakshinamoorthy $S$, Jain AK, Bloom DA, Jaiswal AK. Bach1 competes with Nrf2 leading to negative regulation of the antioxidant response element (ARE)-mediated $\mathrm{NAD}(\mathrm{P}) \mathrm{H}$ :quinone oxidoreductase 1 gene expression and induction in response to antioxidants. J Biol Chem. 2005;280:16891-900.

30. Wang X, Liu J, Jiang L, Wei X, Niu C, Wang R, Zhang J, Meng D, Yao K. Bach1 induces endothelial cell apoptosis and cell-cycle arrest through ROS generation. Oxid Med Cell Longev. 2016;2016:6234043.

31. Ebina-Shibuya R, Watanabe-Matsui M, Matsumoto M, Itoh-Nakadai A, Funayama R, Nakayama K, Muto A, Igarashi K. The double knockout of
Bach1 and Bach2 in mice reveals shared compensatory mechanisms in regulating alveolar macrophage function and lung surfactant homeostasis. J Biochem. 2016;160:333-44.

32. Jiang L, Yin M, Wei X, Liu J, Wang X, Niu C, Kang X, Xu J, Zhou Z, Sun S, et al. Bach1 represses Wnt/ $\beta$-catenin signaling and angiogenesis. Circ Res. 2015;117:364-75.

33. Lee J, Yesilkanal AE, Wynne JP, Frankenberger C, Liu J, Yan J, Elbaz M, Rabe DC, Rustandy FD, Tiwari P, et al. Effective breast cancer combination therapy targeting $\mathrm{BACH} 1$ and mitochondrial metabolism. Nature. 2019;568:254-8.

34. Han W, Zhang Y, Niu C, Guo J, Li J, Wei X, Jia M, Zhi X, Yao L, Meng D. BTB and CNC homology 1 (Bach1) promotes human ovarian cancer cell metastasis by HMGA2-mediated epithelial-mesenchymal transition. Cancer Lett. 2019;445:45-56

35. Wiel C, Le Gal K, Ibrahim MX, Jahangir CA, Kashif M, Yao H, Ziegler DV, Xu X, Ghosh T, Mondal T, et al. BACH1 stabilization by antioxidants stimulates lung cancer metastasis. Cell. 2019;178(330-345):e322.

36. Wei X, Guo J, Li Q, Jia Q, Jing Q, Li Y, Zhou B, Chen J, Gao S, Zhang X, et al. Bach1 regulates self-renewal and impedes mesendodermal differentiation of human embryonic stem cells. Sci Adv. 2019;5:eaau7887.

\section{Publisher's Note}

Springer Nature remains neutral with regard to jurisdictional claims in published maps and institutional affiliations.
Ready to submit your research? Choose BMC and benefit from:

- fast, convenient online submission

- thorough peer review by experienced researchers in your field

- rapid publication on acceptance

- support for research data, including large and complex data types

- gold Open Access which fosters wider collaboration and increased citations

- maximum visibility for your research: over $100 \mathrm{M}$ website views per year

At BMC, research is always in progress.

Learn more biomedcentral.com/submissions 